\title{
Mechanisms Underlying Dysregulation of miR-132 in Alzheimer's Disease
}

\author{
Qiaoyun Song ${ }^{1,3,}$ Juan $\mathrm{Dou}^{2}$, Zixu Mao' ${ }^{1}$ Zhexing Wen ${ }^{2}$ and Wenming $\mathrm{Li}^{1 *}$ \\ ${ }^{1}$ Department of Pharmacology and Chemical biology, Emory University School of Medicine, USA \\ ${ }^{2}$ Department of Psychiatry and Behavioral Sciences, Emory University School of Medicine, USA \\ ${ }^{3}$ Department of Reproductive Genetics, Hebei General Hospital, PR China
}

*Corresponding author: Wenming Li, Department of Pharmacology and Chemical biology, Emory University School of Medicine, USA

\begin{tabular}{|c|c|}
\hline ARTICLE INFO & ABSTRACT \\
\hline Received: 豐 November 11, 2019 & Abbreviations: CREB: cAMP-Response Element Binding Protein; DGCR8: DiGeorge \\
\hline Published: 慧 November 15, 2019 & $\begin{array}{l}\text { Critical Region 8; ERK: Extracellular Signal-Regulated Protein Kinases; FOXO: Forkhead } \\
\text { Box 0; ITPKB: Inositol-Trisphosphate 3-kinase B; MAPK: Mitogen-Activated Protein }\end{array}$ \\
\hline
\end{tabular}

Zhexing Wen, Wenming Li. Mechanisms Underlying Dysregulation of miR-132 in Alzheimer's Disease. Biomed J Sci \& Tech Res 22(5)-2019. BJSTR. MS.ID.003824.

\section{Opinion}

Alzheimer's disease (AD), the most common format of dementia, is an increasingly prevalent and complex neurogenerative disorder in the elderly and among the leading causes of a miserable life quality and death worldly and characterized pathologically by both abnormal plaques consisting of aggregated amyloid $\beta(A \beta)$ and neurofibrillary tangles of hyperphosphorylated tau [1]. microRNAs (miRNAs), small non-coding RNAs that regulate the translation of targeted mRNAs, are predicted to regulate up to $90 \%$ of the genes in humans, suggesting that they may control every cellular process in all cells and tissues of the human body [2]. Not surprisingly, alterations of individual miRNAs have been implicated in the AD pathological condition. The number of miRNAs is dysregulated in the $\mathrm{AD}$ disease conditions. Several neuroprotective miRNAs, especially miR-132, are downregulated in the AD patient brain, while several neurodegenerative miRNAs are upregulated in the same AD context [3]. Identifying what reasons and mechanisms cause the differentiative expressions of miRNAs may be key to the understanding of $\mathrm{AD}$ pathogenesis and the approaching of miRNAs for the AD therapy. Here we take miR-132 as an example to briefly discuss what mechanisms mediate its dysregulation under Alzheimer's conditions.

Interplay of miR-132 with $\mathrm{AD}$ : miR-132 is specifically expressed and enriched in mammalian brains [4]. miR-132 and its paralogue miR-212 gene locates in human chromosome 17. Mature miR132 sequences of 22 base pairs are processed from its precursor sequence of 66 nucleotides. Human miR-132 consists of two homologous miRNAs, i.e., miR-132-5p and miR-132-3p. The latter is a significant part of the miR-132/212 cluster [5]. Several lines of evidence show that miR-132-3p is downregulated with pathologic $\mathrm{AD}$ and associated with neuritic $\mathrm{A} \beta$ plaques and neurofibrillary tangle pathologies in AD brains [6, 7]. miR-212/132 deficiency in a mouse model leads to impaired memory, enhanced tau pathology, and excessed $A \beta$ production/senile plaque formation as seen in AD patients. Mechanism study shows that miR-132 can target and downregulate tau, MAPK, sirt1, FOX01a, ITPKB, PTEN, and FOXO3a, which are implicated in tau production, splicing, and phosphorylation [8-10], $\mathrm{A} \beta$ metabolism and deposition $[8,9]$, or programmed neuronal death [11]. Interestingly, miR-132 is 
consistently upregulated in patients suffering from mild cognitive impairment (MCI), which may be benefit response to the $\mathrm{AD}$ associated stress to maintain brain integrity in the early stage of disease [12]. Other researchers report that this miRNA drops in people with vascular dementia as well $[13,14]$. More importantly, miR-132 seems to protect against toxic $A \beta$ and tau and to enhance the hippocampal long-term potentiation in both rodent models and human neurons [15]. To examine the neuroprotective properties of naturally occurring miRNAs, Dr. Krichevsky's group has demonstrated that miR-132 is the most neuroprotective miRNA among 63 neuronal miRNAs [16]. Collectively, miR-132 has multiple neuroprotective activities, and its alteration aggravates multiple layers of AD pathology at the molecular and functional levels $[6,8]$.

Potential mechanisms underlying miR-132 dysregulation in AD: The level of miR-132 depends on its biogenesis and degradation. miRNA biogenesis is controlled by several tightly coupled sequential steps. Most miRNAs are generated via the canonical pathway consisting of three tightly coupled steps [17]. miRNAs are initially transcribed from their genes by RNA polymerase II as the pri-miRNAs, which typically are over $1 \mathrm{~kb}$ and contain a terminal loop, a stem, and two flanking sides. Drosha and DGCR8 in the microprocessor complex process pri-miRNAs into the pre-miRNAs $[17,18]$. After transported into the cytoplasm by exportin-5, premiRNAs are further processed by the second RNase III enzyme Dicer to generate a double-stranded miRNA duplex of about 22 nucleotides [19]. Either strand of the duplex, i.e., miRNA-5p and miRNA-3p, is loaded into the RNA-induced silencing complex involving Argonaute family proteins to repress mRNA translation or reduce its stability $[20,21]$. miRNA biogenesis is highly regulated, but biogenetical processes and mechanisms underlying individual miRNAs, especially ones associated with $\mathrm{AD}$, are poorly understood. For miR-132 under normal conditions, BDNF can enhance the transcription of pri-miR-132 possibly through the ERK1/2-MSKCREB pathway [22].

However, no study answers which stage of miR-132 biogenesis is dysregulated under $\mathrm{AD}$ conditions. By measuring and analyzing the levels of pri-, pre-, and mature miR-132 under several AD conditions, we have found that the dysregulation of miRNA-132 occurs at the step from its pri- to pre-miRNA (unpublished data). We propose that the altered proteins in the pri-miR-132 microprocessor complex by AD stress deregulate its biogenesis and cause AD-associated pathological changes. To test this hypothesis, we have established a novel system to identify altered proteins in one specific individual miRNA microprocessor complex by using the unique pri-miRNA hairpin-based hybridization precipitation (RHP) technique. Several novel proteins have been identified as regulators for miR-132 biogenesis from the pri-miR-132 microprocessor under $\mathrm{AD}$ conditions (unpublished data), which may be involved in the mechanisms underlying miR-132 dysregulation under $\mathrm{AD}$ conditions although we cannot rule out the possibility of miR-132 dysregulation occurring at the stage of its degradation.
Although Biogen will pursue a regulatory approval for aducanumab because this antibody targeting amyloid in the Phase III EMERGE trial has met its primary endpoint, showing a significant decrease in clinical decline, miR-132 may still offer hope for the novel Alzheimer's treatment [16], but we have to know how to target miR-132 for Alzheimer's therapy because miR-132 is a multifaceted miRNA:

a) More than a dozen targets for miR-132 have been identified beyond the central nervous system [23];

b) Besides as the mediator to regulate neuronal differentiation and maturation and to participate in axon growth, neural migration, and plasticity, miR-132 is implicated in much non-neuronal functioning such as inflammation and angiogenesis [5,24]; and

c) miR-132 may induce neuronal apoptosis and enhance tau phosphorylation under certain AD conditions [25]. Therefore, the investigation of mechanisms underlying alteration of miR132 in AD may not only help us understand the AD pathogenesis but also provide promising therapeutic targets for AD.

Only understanding of the mechanisms underlying dysregulation of miR-132 can help us to correct such a dysregulation, which may serve as more effective therapeutic strategies to address and modify AD pathological processes.

\section{Acknowledgement}

The relevant work is partially supported by grants from NIH [AG058866 (WL), NS095269 and NS107505 (ZM)] and DoD [W81XWH1910353 (ZW)].

\section{References}

1. Lavado, LK, Zhang MH, Patel K, Khan S, Patel UK (2019) Biometals as Potential Predictors of the Neurodegenerative Decline in Alzheimer's Disease. Cureus 11(9): 5573.

2. Provost $P$ (2010) Interpretation and applicability of microRNA data to the context of Alzheimer's and age-related diseases. Aging (Albany NY) 2(3): 166-169.

3. Juzwik CA, S Drake S, Zhang Y, Paradis-Isler N, Sylvester A, et al. (2019) microRNA dysregulation in neurodegenerative diseases: A systematic review. Prog Neurobiol 182: 101664.

4. Lagos-Quintana M, Rauhut R, Yalcin A, Meyer J, Lendeckel W, et al. (2002) Identification of tissue-specific microRNAs from mouse. Current biology 12(9): 735-739.

5. Qian Y, Song J, Ouyang Y, Han Q, Chen W, et al. (2017) Advances in Roles of miR-132 in the Nervous System. Front Pharmacol 8: 770.

6. Salta E, B De Strooper (2017) microRNA-132: a key noncoding RNA operating in the cellular phase of Alzheimer's disease. FASEB J 31(2): 424-433.

7. Patrick E, Rajagopal, Wong H, McCabe C, Xu J, et al. (2017) Dissecting the role of non-coding RNAs in the accumulation of amyloid and tau neuropathologies in Alzheimer's disease. Mol Neurodegener 12(1): p. 51.

8. Hernandez-Rapp J, Rainone S, Goupil C, Dorval V, Smith PY, et al. (2016) microRNA-132/212 deficiency enhances Abeta production and senile plaque deposition in Alzheimer's disease triple transgenic mice. Sci Rep 6: pp. 30953. 
9. Salta E, Sierksma A, Vanden Eynden E, De Strooper B (2016) miR-132 loss de-represses ITPKB and aggravates amyloid and TAU pathology in Alzheimer's brain. EMBO Mol Med 8(9): 1005-1018.

10. Wang Y, Veremeyko T, Wong AH, El Fatimy R, Wei Z, et al. (2017) Downregulation of miR-132/212 impairs S-nitrosylation balance and induces tau phosphorylation in Alzheimer's disease. Neurobiol Aging 51: pp. 156-166.

11. Wong HK, Tatiana Veremeyko, Nehal Patel, Cynthia A Lemere, Dominic M Walsh, et al. (2013) De-repression of FOXO3a death axis by microRNA-132 and -212 causes neuronal apoptosis in Alzheimer's disease. Hum Mol Genet 22(15): 3077-3092.

12. Wu HZ, Ong KL, Seeher K, Armstrong NJ, Thalamuthu A, et al. (2016) Circulating microRNAs as Biomarkers of Alzheimer's Disease: A Systematic Review. J Alzheimers Dis 49(3): 755-766.

13. Sheinerman KS, Tsivinsky VG, Crawford F, Mullan MJ, Abdullah L, et al (2012) Plasma microRNA biomarkers for detection of mild cognitive impairment. Aging (Albany NY) 4(9): 590-605.

14. Lau P, Bossers K, Janky R, Salta E, Frigerio CS, et al. (2013) Alteration of the microRNA network during the progression of Alzheimer's disease. EMBO Mol Med 5(10): 1613-1634

15. Wei Z, Meng X, El Fatimy R, Sun B, Mai D, et al. (2019) Environmental enrichment prevents Abeta oligomer-induced synaptic dysfunction through mirna-132 and hdac3 signaling pathways. Neurobiol Dis 134 pp. 104617.

16. El Fatimy R, Li S, Chen Z, Mushannen T, Gongala S, et al. (2018) MicroRNA-132 provides neuroprotection for tauopathies via multiple signaling pathways. Acta Neuropathol 136(4): 537-555.

\section{ISSN: 2574-1241}

DOI: 10.26717/BJSTR.2019.22.003824

Wenming Li. Biomed J Sci \& Tech Res

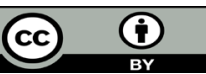

This work is licensed under Creative Commons Attribution 4.0 License

Submission Link: https://biomedres.us/submit-manuscript.php
17. Kwon SC, Nguyen TA, Choi YG, Jo MH, Hohng S, et al. (2016) Structure of Human DROSHA. Cell 164(1-2): 81-90.

18. Yang Q, Li W, She H, Dou J, Duong DM, et al. (2015) Stress induces p38 MAPK-mediated phosphorylation and inhibition of Drosha-dependent cell survival. Mol Cell 57(4): 721-734.

19. Lund E, JE Dahlberg (2006) Substrate selectivity of exportin 5 and Dicer in the biogenesis of microRNAs. Cold Spring Harb Symp Quant Biol 71: 59-66.

20. Meijer HA, EM Smith, M Bushell (2014) Regulation of miRNA strand selection: follow the leader? Biochem Soc Trans 42(4): 1135-1140.

21. Ren G, Y Kang, (2013) A one-two punch of miR-126/126* against metastasis. Nat Cell Biol 15(3): 231-233.

22. Yi LT, Li J, Liu BB, Luo L, Liu Q et al. (2014) BDNF-ERK-CREB signalling mediates the role of miR-132 in the regulation of the effects of oleanolic acid in male mice. J Psychiatry Neurosci 39(5): 348-359.

23. Hewitson JP , Shah KM , Brown N , Grevitt P , Hain S , et al. (2019) miR-132 suppresses transcription of ribosomal proteins to promote protective Th1 immunity. EMBO Rep 20(4).

24. Che F, Du H, Zhang W, Cheng Z, Tong Y, et al. (2018) MicroRNA-132 modifies angiogenesis in patients with ischemic cerebrovascular disease by suppressing the NFkappaB and VEGF pathway. Mol Med Rep 17(2): 2724-2730.

25. Liu DY, L Zhang (2019) MicroRNA-132 promotes neurons cell apoptosis and activates Tau phosphorylation by targeting GTDC-1 in Alzheimer's disease. Eur Rev Med Pharmacol Sci 23(19): 8523-8532.

$\begin{array}{ll}\text { BIOMEDICAL } & \text { Assets of Publishing with us } \\ \text { RESEARCHES } & \text { - Global archiving of articles } \\ \text { - Immediate, unrestricted online access }\end{array}$

